\title{
Clinical Characteristics and Microbiological Analysis of Urinary Tract Infection in Children of 2 Months to 12 Years: A Prospective Study
}

\author{
Rukhayya Nasser ${ }^{1}$, Manakkattu TP Mohammed ${ }^{2}$, Radhamani K Veettil ${ }^{3}$, Ravikumar Payora ${ }^{4}$, Ambily S Jacob ${ }^{5}$
}

\begin{abstract}
Objectives: To study the clinical characteristics and etiological agents of urinary tract infection (UTI) in children of 2 months to 12 years, and to find the prevalence of vesicoureteric reflux (VUR) in children with UTI.

Materials and methods: This prospective study was conducted among 47 children with culture-positive UTI in children between 2 months to 12 years. All children attending the pediatric outpatient department (OPD) of Government Medical College Hospital, Kannur, Kerala, India, were enrolled. Clinical and bacteriological profile of all cases were evaluated and ultrasonogram (USG) abdomen/micturating cystourethrogram (MCU) were done for these patients to find the predisposing factors associated with recurrent infections like VUR and posterior urethral valve.

Results: A total of 47 children were enrolled, of which 25 (53.19\%) children were below 1 year of age. Male to female ratio was 2.1:1. The most common symptom was fever, and Escherichia coli (65.9\%) was the most common organism isolated. Within the cohort, $23.40 \%$ of children had recurrent UTI and $19.14 \%$ showed VUR.

Conclusion: Urinary tract infection is a very common infection in infants and children. It is equally important that we treat the child with antibiotics and investigate for any underlying causes such as VUR or obstructive uropathy.

Keywords: Micturating cystourethrogram, Urinary tract infection, Vesicoureteric reflux.

Pediatric Infectious Disease (2019): 10.5005/jp-journals-10081-1219
\end{abstract}

\section{INTRODUCTION}

Urinary tract infection (UTI) is a common cause of febrile illness among the pediatric age-group (third most common), and it accounts for $0.7 \%$ of all outpatient's clinic visits. In the emergency department, up to $14 \%$ of children are admitted because of UTI either due to direct infection or indirectly due to its associated complications. ${ }^{2}$ Knowledge of the exact incidence and prevalence of UTI among children is essential for pediatricians because the diagnosis of the diagnosis may be challenging on a clinical basis, and the incidence and prevalence will determine the cost-benefit effect of investigating the condition. Incidence of UTI is around 1\% in boys and $1-3 \%$ in girls. During infancy the male to female ratio is 2.8-5.4:1. After which, there is a female preponderance, with a male to female ratio of 1:10. In boys, most UTIs occur within the first year of life; UTIs are much more common in uncircumcised boys, especially within 1 year of age. In girls, the first UTI usually occurs by age of 5 years, which peaks during infancy and toilet training period. ${ }^{3}$

Colonic bacteria are the most common etiological agent for UTI. Approximately $75-90 \%$ of UTI in girls are caused by $E$. coli, followed by Klebsiella and Proteus species. Although E. coli is the most common organism in males, some studies have reported that in boys older than 1 year, Proteus is as common a cause as E. coli; others report a preponderance of gram-positive organisms in boys. Staphylococcus saprophyticus and Enterococcus are uropathogens in both sexes. The risk factors associated with UTI are females, uncircumcised boys, vesicoureteral reflux (VUR), dysfunctional voiding, obstructive uropathies, urethral instrumentation and manipulation, wiping from back to front in girls, tight clothing, pinworm infestation, constipation, bacteria

\footnotetext{
${ }^{1-5}$ Department of Pediatrics, Government Medical College, Kannur, Kerala, India
}

Corresponding Author: Manakkattu TP Mohammed, Department of Pediatrics, Government Medical College, Kannur, Kerala, India, Phone: +91-9446844884, e-mail:drmtpmohd@yahoo.com

How to cite this article: Nasser R, Mohammed MTP, Veettil RK, et al. Clinical Characteristics and Microbiological Analysis of Urinary Tract Infection in Children of 2 Months to 12 Years: A Prospective Study. Pediatr Inf Dis 2019;1(3):79-81.

Source of support: Nil

Conflict of interest: None

with P fimbriae, anatomic abnormality (labial adhesion), and neuropathic bladder. ${ }^{3}$

Acute pyelonephritis has been diagnosed in two third of febrile UTIs in early childhood. ${ }^{4}$ Published data which have used renal parenchyma nuclear scans like dimercaptosuccinic acid (DMSA) and diethylenetriamine pentaacetic acid (DTPA) conclude that more than $75 \%$ of children under 5 years of age with febrile UTI have pyelonephritis. ${ }^{5-7}$ Pyelonephritis leads to renal scarring in $27 \%$ to $64 \%$ of children with UTI, even in the absence of the underlying urinary tract abnormalities. ${ }^{8,9}$ Most UTIs that lead to scarring or diminished kidney growth occurred in children less than 4 years, especially within the first year of life. ${ }^{6,9}$ It is essential to diagnose UTIs in febrile children at the earliest and intervene to reduce the potential of lifelong morbidity. Optimum treatment results in symptomatic relief, prevents progressive renal damage, and urosepsis with immediate bacterial eradication. ${ }^{10}$ Progressive renal damage from unrecognized pyelonephritis may lead to 
hypertension and chronic renal failure later in life. A study from Sweden showed that focal renal scarring caused by pyelonephritis in children carried $23 \%$ risk of hypertension, $10 \%$ risk of endstage renal disease, and $15 \%$ risk of toxemia during pregnancy as an adult. ${ }^{11}$ Approximately, $13-15 \%$ of end-stage renal disease is thought to be related to UTI in childhood, which was often unrecognized and therefore not adequately treated. ${ }^{12}$

Vesicoureteral reflux is defined as the backward flow of urine from the bladder into the ureter. Vesicoureteric reflux is present in approximately $30 \%$ of females who had a UTI and in $5-15 \%$ of infants with antenatally detected hydronephrosis. Vesicoureteric reflux predisposes to pyelonephritis by facilitating the transport of bacteria from the bladder to the upper urinary tract. The inflammatory reaction caused by pyelonephritis can result in renal injury or scarring, which is also termed reflux-related renal injury or reflux nephropathy. Of the children with febrile UTI, those with VUR are three times more likely to develop renal injury compared to those without VUR, which can be identified by doing an micturating cystourethrogram (MCU).

The present study aimed at identifying the clinical and bacteriological profile of children with UTI in the age-group of 2 months to 12 years.

\section{Materials and Methods}

It was a prospective study. Inclusion criteria were to take all culturepositive cases of UTI between the age-group of 2 months and 12 years. We excluded children whose parents were not willing to take part in the study. Children with culture-positive UTI between the age-group of 2 months and 12 years attending the pediatric OPD of Government Medical College Hospital, Kannur during a 1-year period (from April 1, 2018, to March 31, 2019) were enrolled. The sample size was calculated using the formula $4 p(1-p) / d 2$ where " $p$ " is the prevalence and " $d$ " is the absolute precision. A detailed proforma for collecting data related to age, sex, birth weight, bowel habits, etc., were prepared. A detailed clinical history related to the onset of fever, duration, associated symptoms such as nausea, vomiting, diarrhea, urinary disturbances, and other system involvement was obtained. Routine physical examination was done in all enrolled children.

Complete blood counts, urine analysis, and urine culture and sensitivity were done for all patients. Midstream urine samples were used for routine and culture analysis. Urine culture was done by BACTEC method. In patients whose urine routine was positive for UTI (pus cells >5) were started on oral empirical antibiotics, such as cefixime, and after culture reports antibiotics were adjusted accordingly. An USG of the abdomen, renal function test, and MCU were done in all cases to identify abnormalities such as VUR and posterior urethral valve per the guidelines laid down by the Indian Society of Nephrology (Tables 1 to 3 ).

\section{Statistical Analysis}

The data were entered to Microsoft Excel and were analyzed using SPSS software. The results were described using frequencies and proportions. Inferential statistics such as Chi-square test and Fisher exact test were used to test the significance of association between various etiological factors and occurrence of UTI.

\section{Results}

A total of 47 children studied. Of them, 25 (53.19\%) children were below 1 year and 22 (46.80\%) above 1 year of age; 26 (55.31\%) were
Table 1: Clinical profile of children with urinary tract infection

\begin{tabular}{lll}
\hline Clinical features & $\begin{array}{l}\text { Number of } \\
\text { patients }(n=47)\end{array}$ & \begin{tabular}{l} 
Percentage \\
\hline Fever
\end{tabular} \\
Dysuria & 30 & 63.82 \\
Vomiting & 19 & 40.42 \\
Irritability & 8 & 17.02 \\
Increased frequency of micturition & 2 & 4.2 \\
Urgency & 5 & 10.63 \\
Constipation & 5 & 10.63 \\
\hline
\end{tabular}

Table 2: Demographic data

\begin{tabular}{ll}
\hline Age & \\
$<1$ year & $25(53.19 \%)$ \\
$>1$ year & $22(46.80 \%)$ \\
Gender & \\
Male & $26(55.31 \%)$ \\
Female & $21(44.6 \%)$ \\
\hline
\end{tabular}

Table 3: Bacteriological profile of children with urinary tract infection

\begin{tabular}{|c|c|c|c|}
\hline $\begin{array}{l}\text { Bacterial } \\
\text { isolates }\end{array}$ & $\begin{array}{l}\text { Number of } \\
\text { isolates }\end{array}$ & Percentage & Antibiotic sensitivity \\
\hline Escherichia coli & 31 & 65.95 & $\begin{array}{l}\text { Cefpodoxime, } \\
\text { ofloxacin, piperacillin- } \\
\text { tazobactam, } \\
\text { amikacin, ceftriaxone, } \\
\text { nitrofurantoin }\end{array}$ \\
\hline Klebsiella spp. & 8 & 17.02 & $\begin{array}{l}\text { Amikacin, ofloxacin, } \\
\text { nitrofurantoin }\end{array}$ \\
\hline $\begin{array}{l}\text { Proteus } \\
\text { mirabilis }\end{array}$ & 4 & 8.51 & Ciprofloxacin, amikacin \\
\hline $\begin{array}{l}\text { Coagulase- } \\
\text { negative } \\
\text { Staphylococcus }\end{array}$ & 2 & 4.25 & Ofloxacin \\
\hline Pseudomonas & 2 & 4.25 & Ofloxacin \\
\hline
\end{tabular}

males and 21 (44.6\%) were females. Of the 26 male children, only $5(19.2 \%)$ males had undergone circumcision.

Symptomatically $63.82 \%$ of children presented with fever, $40.42 \%$ with dysuria, $17.02 \%$ with vomiting, $10.6 \%$ with increased frequency of micturition and urgency, and $4.25 \%$ with irritability. During the antenatal period, $14.8 \%$ of them had abnormal findings in ultrasound, such as hydronephrosis.

Escherichia coli was the most common organism 65.95\%) identified in all culture positive followed by Klebsiella (17.02\%), Proteus species (8.51\%), coagulase-negative Staphylococci (4.25\%), and Pseudomonas in $4.25 \%$. Escherichia coli was sensitive to ofloxacin, amikacin, nitrofurantoin, ceftriaxone, and piperacillintazobactam. Klebsiella was sensitive to nitrofurantoin, cefixime, ofloxacin, and amikacin. Both E. coli and Klebsiella were resistant to amoxicillin-clavulanic acid. Among the cases, $8.5 \%$ had to be treated with multiple drugs in order to get a sterile culture. Average duration of treatment was about 7-10 days.

Urine stream was good in $87.27 \%$ children but was poor in $12.76 \%$ (as observed by parents), which was important as children with poor urine stream have more chances of having lower urinary tract anomalies such as posterior urethral valve which in turn can increase the chances of UTI. Proportion of children with 
constipation was $12.76 \%, 29.7 \%$ (14) children had pallor, $42.55 \%$ (20) of children had recurrent UTI out of which only $3(6.3 \%)$ had antenatal hydronephrosis. Of all the children with UTI, the USG abdomen showed abnormal findings (hydronephrosis and hydroureteronephrosis) in 13 (27.65\%), and 9 (19.14\%) children had VUR.

Among children with VUR, 22\% had grade VUR, 44\% grade III, and $33 \%$ grade IV. For grades I and II, antibiotic prophylaxis was given with cephalexin and MCU was repeated; whereas in case of grades III and IV, after starting on prophylaxis if the child was symptomatic, the treatment of choice was pyeloplasty.

\section{Discussion}

Urinary tract infections are one of the most common, potentially serious infections of childhood. They can cause acute morbidity as well as long-term complications including hypertension and impaired renal function. Prevalence of culture-positive UTI in our study, $<1$ year -25 (53.19\%) and $>1$ year -22 (48.80\%), which is comparable to Gupta et al. ${ }^{13}$ and Ghadage et al. ${ }^{14}$ who found maximum number of patients (56.5 and $37.7 \%$, respectively) in the age-group of less than 1 year. However, Sharma et al., ${ }^{15}$ Malla et al., ${ }^{16}$ Singh et al., ${ }^{17}$ and Chand et al. ${ }^{18}$ have reported maximum number of patients between 1 year and 5 years (varying from 35 to $50 \%$ ) in this age-group. Our study had shown male to female ratio of 1.2:1, which is actually not consistent with other studies which documented higher rates of infection in females, with a male to female ratio varying from 1:1.3 to $1: 2$. This is probably because our study had more affected children $<1$ year, and males are more susceptible to UTI in the first year of life; $80.76 \%$ were uncircumcised males compared to $19.24 \%$ circumcised males.

Fever was the most common symptom in our study (63.82\%). Other studies have also found it to be the most common symptom, i.e., reported in $45-87 \%$ of their patients. ${ }^{13-15}$ The other common symptoms noted were $40.42 \%$ with dysuria, $17.02 \%$ with vomiting, $10.63 \%$ with increased frequency of micturition and urgency, and $4.25 \%$ with irritability that correlates with other studies. Infants presented with nonspecific symptoms such as fever, vomiting, poor feeding, diarrhea, and irritability, while older children had urinary symptoms and pain in abdomen with or without fever.

In our study, E. coli (65.95\%) was the commonest organism isolated in both the genders and in all the age-groups, followed by Klebsiella (17.02\%). This finding has also been observed in studies from other parts of India. ${ }^{15-17}$ Therefore, E. coli remains the most common uropathogen. As also reported in other studies, in our study Proteus was isolated only in males. This is because of the frequent colonization of the prepuce in males.

Twelve (25.5\%) children had recurrent UTI and 9 children (19.14\%) showed VUR. According to previous studies done in Indian children, ${ }^{18}$ primary VUR occurs in less than $1 \%$ of the general population and as many as $50 \%$ of children who present with recurrent UTI will have VUR. More than $75 \%$ of children under 5 years of age with febrile UTI have pyelonephritis, and higher risk of renal scarring is seen in children under 3 years of age with recurrent UTI. ${ }^{18}$

\section{Conclusion}

Urinary tract infection is a very common infection in infants and children. It is equally important to treat the child with UTI and also look for any underlying cause like VUR or obstructive uropathy which should not be missed. Prevalence of UTI is more common in $<1$ year males. The most common organism isolated was E. coli.
The most common symptom on presentation was fever. In all culture-positive UTI, it is always important to do an USG scan and MCU to look for pyelonephritic changes, renal scarring, and VUR, and treat them at the earliest.

\section{References}

1. Freedman AL. Urologic diseases in North America project: trends in resource utilization for urinary tract infections in children. J Urol 2005;173(3):949-954. DOI: 10.1097/01.ju.0000152092.03931.9a.

2. Hoberman A, Charron M, Hickey RW, et al. Imaging studies after a first febrile urinary tract infection in young children. $N$ Engl J Med 2003;348(3):195-202. DOI: 10.1056/NEJMoa021698.

3. Elder JS. Urinary tract infections. In: Kliegman RM, Stanton BF,St, Geme JW, et al. Nelson textbook of pediatrics. 19 ed., Philadelphia: Elsevier Saunders; 2011. pp. 1829-1934.

4. Keren R. Imaging and treatment strategies for children after first urinary tract infection. Curr Opin Pediatr 2007;19(6):705-710. DOI: 10.1097/MOP.0b013e3282f1dcd7.

5. Williams GJ, Lee A, Craig JC. Long-term antibiotics for preventing recurrent urinary tract infection in children. Cochrane Database Systematic Reviews [internet] 2001(4):CD001534. DOI: 10.1002/14651858.CD001534.

6. Shaw KN, Gorelick MH. Urinary tract infection in the paediatric patient. Paediatric clinics of North America 1999;46(6):1111-1123. DOI: 10.1016/ s0031-3955(05)70177-2.

7. Benador D, Benador N, Siosman DO, et al. Cortical scintigraphy in the evaluation of renal parenchymal changes in children with pyelonephritis. J Pediatr 1994;124(1):17-20. DOI: 10.1016/s00223476(94)70248-9.

8. Majd M, Rushton HG, Jantausch B, et al. Relationship among vesicoureteral reflux, P-fimbriated Escherichia coli and, acute pyelonephritis in children with febrile urinary tract infection. J Pediatr 1991;119(4):578-585. DOI: 10.1016/s0022-3476(05)82407-2.

9. Rushton HG, Majd M, Jantausch $B$, et al. Renal scarring following reflux and non reflux pyelonephritis in children: evaluation with 99m technetium dimercaptosuccinic acid scintigraphy. J Urol 1992;147(5):1327-1332. DOI: 10.1016/s0022-5347(17)37555-9.

10. Berg UB. Long term follow-up of renal morphology and function in children with recurrent pyelonephritis. J Urol 1992;148(5 Pt 2): 1715-1720. DOI: 10.1016/s0022-5347(17)37012-x.

11. Malhotra SM, Kennedy WA. Urinary tract infections in children: treatment. Urol Clin North Am 2004;31(3):527-534. DOI: 10.1016/j. ucl.2004.04.013.

12. Jacobson SH, Eklof O, Eriksson CG, et al. Development of hypertension and uraemia after pyelonephritis in childhood: 27 year follow up. BMJ 1989;299(6701):703-706. DOI: 10.1136/bmj.299.6701.703.

13. Gupta P, Mandal J, Krishnamurthy $S$, et al. Profile of urinary tract infections in paediatric patients. Indian J Med Res 2015;141(4): 473-477. DOI: 10.4103/0971-5916.159299.

14. Ghadge DP, Nale SS, Kamble DS, et al. Study of aetiology and antibiogram of uropathogens in children-a retrospective analysis. J Clin Diagn Res 2014;8(1):20-22.

15. Sharma A, Srestha S, Upadhyay S, et al. Clinical and bacteriological profile of urinary tract infection in children at Nepal medical college teaching hospital. Nepal Med Coll J 2011;13(1):24-26.

16. Malla KK, Sharma MS, Malla T, et al. Clinical profile, bacterial isolates and antibiotic susceptability pattern in urinary tract infection in children-hospital based study. J Nepal Paediatr Soc 2008;28(2):52-61. DOI: 10.3126/jnps.v28i2.1388.

17. Singh SD, Madhup SK. Clinical profile and antibiotic sensitivity in childhood urinary tract infection at Dhulikhel hospital. Kathmandu Uni Med J 2013;11(44):319-324. DOI: 10.3126/kumj.v11i4. 12541.

18. Chand DH, Rhoades T, Poe SA, et al. Incidence and severity of vesicoureteral reflux in children related to age, gender, race and diagnosis. J Urol 2003;170(4 Pt 2):1548-1550. DOI: 10.1097/01.ju.000 $0084299.55552 .6 \mathrm{c}$. 